\section{Culture in danger}

\author{
Terence R. Lee
}

Risk Acceptability According to the Social Sciences. By Mary Douglas. Russell Sage Foundation: 1986. Pp. 115. Distributed by Basic Books, New York, pbk \$6.95.

RISK assessment and the concept of acceptable risk are much in vogue of late, and there are few learned scientific societies that have not felt the need to confer on the subject. But this book is not in the mainstream of such considerations and does not mention probabilistic risk assessment, fatal accident frequency rates or $\mathrm{LD}_{50}$ tests. Rather, it is about risk perceptions as products of culture.

In the past, approaches to risk through the social sciences have been largely dominated by psychometric studies of perceived risk and by classical utility theory with its later refinements. Psychologists, economists and others in the field are acutely aware of the vast discrepancies between the public's idea of risks and the scientific estimates of the risk assessor. But they decline to attribute them to public ignorance or "irrationality".

Workers in comparative risk perception have emphasized the profile of qualities that go to make up the "meaning" that a hazardous activity has for people. They demonstrate, empirically, that (for example) voluntariness, and familiarity with the risk, its catastrophic potential, its threat to self or to society and the immediacy of its effects are all potent intervening variables. In utility theory, the thrust is towards the complex trade-offs that people make between costs (including risks) and benefits, together with, for example, the "concept of bounded rationality" which explains the changes in the trade-off when the bottom line has to be preserved.

Both of these approaches and more besides are admirably reviewed in Mary Douglas's book. Their limitations are exposed ruthlessly but politely. The author is neither a psychologist nor an economist (despite her erudition in these fields) but an anthropologist. She argues that "...what is needed is to persuade the two sets of analysts that there is a mediating element, culture, which is worthy of their combined attention". This is undeniable, though one may be forgiven for mentioning that the book's somewhat singleminded proselytization of an anthropological perspective may itself demonstrate the force of its central argument - there are no stronger cultural influences on the perception of risk than disciplinary affiliations!

In defence of psychology it has to be said that, although it has shamefully neglected the importance of social factors, it is

far from unaware of them. It is a parody to suppose that psychologists expect to identify explanatory variables that are determined genetically or in early childhood, and thereafter become part of an enduring personality. What they do seek, however, are broad generalizations, and they certainly recognize that the qualities of familiarity and voluntariness, for example, are culturally determined. Further, the systematic differences in perception between members of different cultural groups (namely the League of Women Voters, upwardly mobile businessmen, students and "experts") were demonstrated by psychologists some years ago. Much of personality is internalized culture.

Once again, a great deal depends on the most profitable level of analysis; there is a

\section{Crusading appeal}

\section{Alexandra Dixon \& Brian Bertram}

Animal Extinctions: What Everyone Should Know. Edited by R.J. Hoage. Smithsonian Institution Press/Eurospan, London: 1986. Pp.192. Pbk\$10.95, £9.45.

The Last Extinction. Edited by Les Kaufman and Kenneth Mallory. MIT Press 1986. Pp.208. \$16.95, £12.95.

THE conservation ethic can be likened to a new religion - not in being based on faith, but in the vigour with which those who are convinced of its necessity strive to persuade others to join them. The target is the unconverted general public, the many uninformed, uninterested or unsocial individuals who persist in contributing directly and indirectly to the destruction of the Earth's natural resources, particularly its living resources. Unlike the religious missionary, conservationists are able to marshal a formidable array of scientific and economic arguments to support the cause. The need is for these arguments to be put across to the general public, and urgently.

These two collections of symposium and lecture papers aim to meet this need. The first, Animal Extinctions, will arm the already converted. It contains an assemblage of information on the theory and application of conservation biology, covering such topics as strategies for preserving species in the wild, genetics, sustainable exploitation of wildlife and the economic value of species to mankind. Conservation biologists will have heard much of it before, partly because the symposium was held as long ago as 1982 , and the material was not new then. The general public will find its presentation dull and the arguments rather heavy going, but it is useful to have this authoritative textbook available at last.

For the unconverted, The Last Extinc- sense in which it helps very little to argue that racing drivers, driving-school instructors and housewives all have different perceptions of traffic risks because they are conditioned by different cultural backgrounds. The answer must surely lie in the classification of cultures in terms of the constructions they put upon different hazards - and why. Mary Douglas has made an excellent start in this direction. It has to be added, though, that the exercise will have to "go empirical" if it is to make progress beyond this set of signposts which at present do little more than point clearly and convincingly in the right direction.

Terence R. Lee is a Professor in the Department of Psychology, University of Surrey, Guildford GU2 $5 X H, U K$.

tion is better directed and more effectively evangelical. The editors state in their first paragraph that their aim is to persuade people to rearrange their priorities to avert the threat of mass extinctions, and the contributors set about doing precisely that. The eight public lectures given in Boston, Massachusetts, in 1984 were delivered by a good mixture of representatives from government agencies and the academic, zoo, aquarium and botanical communities in the United States. Using a variety of natural habitats and species to illustrate their points, the authors collectively argue that the looming threat of mass extinctions is not a natural event, that it is of fundamental concern to us all and that urgent action is required, to which end they provide clear recommendations and a useful directory of conservation organizations.

While preaching the same overall message, each chapter deals with a distinct issue. "Why the Ark is Sinking" discusses the crucial difference between natural and unnatural extinctions, and why we should care. A chapter on the Amazon illustrates the nitty-gritty realities of local poverty, conflict of interests and ill-considered development, and gives the reader a real idea of the factors involved in conservation on the ground. But conservation is not only about saving exotic species in faraway lands. For instance, few North Americans realize that at least 25 species and sub-species of vertebrate have become extinct in their continent since 1950.

The Last Extinction is compelling reading. It is well written, and attractively presented with a glossy cover and lots of pictures. Absorbing the arguments presented by the authors is quite painless, which is why the book is so effective. The man in the street will enjoy it; he will also learn a lot. He may also join the crusade. We must all hope so.

Alexandra Dixon and Brian Bertram are at The Zoological Society of London, Regents Park, London NWI $4 R Y$, UK. 